\title{
TRADISI PUNGGAHAN MENJELANG RAMADHAN
}

(Studi di Desa Bedono Kecamatan Jambu Kabupaten Semarang)

\author{
Salma Al Zahra Ramadhani, Nor Mohammad Abdoeh \\ Institut Agama Islam Negeri Salatiga \\ salmaazzahra39@gmail.com
}

\begin{abstract}
"Punggahan" comes from the word 'munggah' (Javanese) which means to go up or enter a bigher place. According to the world 'munggab' implied a change in the direction be better than the "sya'ban" month to boly month of Ramdhan and increase in faith during Ramdhan fasting. Punggaban is a tradition of sending prayers to ancestors who have died before the coming of Ramadhan, meant as a tradition of praying and giving thanks to the glorious month of Ramadhan the moon which is always awaited by its arrival in the world especially Muslims, including Muslims in Indonesia. Various preparations were made to welcome thr arrival of the month of Ramadhan including Punggahan. Punggahan aims to remind muslims that Ramadhan is coming soon, and also send prayers for people who have died. The "pungghan" tradition was introduced by Sunan Kalijaga when spreading islam in Java at the time Sunan Kalijaga used the method of cultur acculturation when spreanding Islam. Punggahan usually done in their respective homes by inviting relatives and neighbors and a kyai to lead thablil and prayer.The menu that must be provided when uploading is apem, pasung. Pisang and ketan the four mandatory menus that must be available at the time of Pungghan. The menu that is brought during Punggahan has is own meaning by welcoming the coming of exist when Punggahan so that the meaning contained can be conveyed and can be known by readers all the word.
\end{abstract}

Key Words : Punggahan, Tradition, Ramadhan, Java, and Prayer

Abstrak

Punggahan berasal dari kata Munggah(bahasa jawa) yang artinya naik, mancat, atau memasuki tempat yang lebih tinggi. Sesuai kata Munggah tersebut tersirat makna perubahan kearah yang lebih baik dari bulan Sya'ban menuju ke bulan suci Ramdhan dan untuk peningkatan iman selama melakukan ibadah puasa Ramadhan.Punggahan merupakan tradisi mengirim doa kepada leluhur yang sudah meninggal dunia menjelang datangnya bulan Ramadhan, di maksudkan sebagai tradisi berdoa dan bersyukur naik ke bulan mulia, yaitu bulan suci Ramadhan bulan yang selalu di tunggu kedatangannya di seluruh dunia terutama oleh umat muslim tidak terkecuali Muslim di Indonesia. Berbagai persiapan pun dilakukan untuk menyambut datangnya Ramadhan di antaranya adalah punggahantradisi ini bertujuan untuk mengingatkan para umat Islam bahwa Ramadhan akan segera tiba, dan juga untuk mengirim doa untuk orang-orang yang telah meninggal dunia. Tradisi punggahan diperkenalkan oleh Sunan Kalijaga saat menyebarkan agama Islam di wilayah Jawa terutama Jawa Tengah saat itu Sunan Kalijaga menggunakan metode akultrasi budaya saat penyebaran agama Islam.Punggahan biasanya dilakukan di rumah, masjid ataupun mushola dengan mengundang sanak saudara dan tentangga sekitar serta seorang kyai untuk memimpin tahlil dan doa. Menu yang wajib disediakan saat punggahan adalah Apem, Pasung, Pisang Raja, dan Ketan keempat menu wajib yang harus ada pada saat punggahan tersebut. Menu yang dibawa saat punggahan ini memiliki makna tersendiri dengan menyambut datangnya bulan Ramadhan maka dari itu menu ini wajib ada ketika punggahan agar makna yang terkandung dapat tersampaikan dan dapat membersihkan jiwa untuk menuju bulan yang mulia yaitu bulan Ramadhan yang dirayakan oleh umat Islam.

Kata Kunci : Punggahan, Tradisi, Ramadhan, Jawa dan Doa 


\section{PENDAHULUAN}

Tradisi adalah sesuatu kebiasaan yang ada di masyarakat baik yang berkembang menjadi adat kebiasaan atau dengan ritual agama lainnya dalam arti lain tradisi atelah menjadi sesuatu yang dilakukan sejak lama dan menjadi bagian dari kehidupan masyarakat dan secara turun temurun. Tradisi itu merupakan hasil ijtihad dari ulama, cendikiawan, budayawan dan orang-orang islam yang termasuk kedalam ulil albab. ${ }^{1}$ Menurut Funk and Wagnalss seperti yang dikutip oleh Muhaimin tentang istilah tradisi di maknai sebagai pengetahuan, doktrin, kebiasaan, praktek dan yang dipahami sebagai pengetahuan yang diwariskan secara turun temurun dengan cara dan praktek tersebut. ${ }^{2}$

Tradisi Islam merupakan proses perkembangan dinamika agama dalam mengatur pemeluk agama islamdan dalam etika berkehidupan sehari-hari. Tradisi Islam lebih mengarah pada peraturan yang ringan dan tidak memaksa terhadap pemeluknya jika pemeluknya tidak mampu. Menurut pemikiran Barth bahwa suatu tradisi bersifat Islami ketika pelakunya mengaku bahwa yang dilakukannya berjiwa Islami. Walaupun kita banyak rmacam-macam tradisi yang tidak diproduksi oleh Islam sendiri yang masih tetap dilakukan oleh masyarakat sekitar. Budaya Jawa yang kental dengan budaya Hindu ini diusung dari para Walisongo pada saat penyebaran dakwah Islam. ${ }^{3}$

Memahami tradisi banyak melihat betapa banyaknya tradisi yang memberi manfaat demi keberlangsungannya tatanan dan nilai tradisi yang telah diwarisakan secara turuntemurun di akui dalam kaidah ilmu Ushul Fiqh bahwa punggahan masuk kedalamnya, ${ }^{4}$ masayarakat banyak yang memahami tradisi dan budaya sehingga tidak terlalu banyak perbedaan yang menonjol. Menurut Kuntowijoyo budaya adalah karya hasil ciptaan manusia dengan menggunakan jiwa dan raganya yang menyatakan diri dalam kehidupan manusia menuju ke arah terwujudnya kesejahteraan manusia baik individu maupun masyarakat. ${ }^{5}$

Tradisi menjadi sumber budaya dalam berakhlak dan budi pengerti manusia dalam perbuatan dan sikapnya di lingkungan masyarkat sekitarnya sebagai motivasi sesorang dalam beradapatasi di suatu wilayh itu sendiri. ${ }^{6}$ Dalam Hukum Islam tradisi dikenal dengan kata Urf ysecara bahasa yaitu "sesuatu yang dipandang baik dan diterima oleh akal sehat" sedangkan secara istilahUrfyaitu " sesuatu yang tidak asing lagi bagi satu masyarakat karenatelah menjadi kebiasaan dan menyatu dengan kehidupan mereka baik berupa perkataan atau perbuatan". ${ }^{8}$ Menurut Ulama 'Usuliyyin Urf adalah sesuatu yang bisa dipahami oleh manusia dan sekelompok manusia yang melakukannya di kehidupan seharihari baik itu melalui perbuatan, perkataan atau meninggalkan. ${ }^{9}$ Al-Urf sama dengan adat

\footnotetext{
${ }^{1}$ Ahmad Syafie Ma'arif, Menembus Batas Tradisi Menuju Masa Depan Yang Membebaskan Refleksi Atas Pemikiran Nur Cholis Majid (Jakarta: Penerbit Buku Kompas, 2006), 99.

${ }^{2}$ Muhaimin AG, Islam Dalam Bingkai Budaya Lokal Potret Dari Cirebon, Terj. Suganda (Ciputat Tangerang: PT Logos Wacana Ilmu, 2001), 11.

${ }^{3}$ Muhammad Nur Hidayat, Lebih Dalam Tentang Nahdhatul 'Ulama (Surabaya: Bina Aswaja, 2012), 2.

${ }^{4}$ Muhammad Sholikhin, Misteri Bulan Suro Prespektif Islam Jawa, (Yogyakarta: Penerbit Narasi, 2010), 264.

${ }^{5}$ Kuntowijaya, Budaya Dan Masyarakat (Yogyakarta: Tiara Wacana, 2006), 3.

${ }^{6}$ Bey Arifin, Hidup Setelab Mati (Jakarta: Pt Dunia Pustaka, 1984), 84.

7 Rasyad Hasan Khalil, Tarikh Tasyri (Jakarta: Grafindo Persada, 2009), 167.

${ }^{8}$ Satria Efendi, Ushul Fiqh (Jakarta: Grafindo Pustaka, 2005), 153.

${ }^{9}$ Maskhur Anhari, Ushul Figh (Surabaya: CV Smart, 2008), 110.
} 
istiadat yaitu sesuatu yang dikenal oleh manusia dan menjadi sebuah tradisi yang dapat diterapakan di kehidupan seperti ucapan, perbuatan dan pantangan. ${ }^{10}$

Menurut peneliti punggahan penting dimaknai oleh generasi millenial yaitu generasi manusia yang lahir dengan rentang tahun antara 1980-1999 masehi yang saat ini menjadi harapan masa depan bangsa. Namun banyak generasi millennial saat ini yang lupa akan budaya atau tradisi dalam daerahnya. Menurut Dr. Sucipto Hadi Purnomo Dosen Bahasa dan Sastra Jawa Universitas Negeri Semarang bahwa generasi millennial agar tidak kehilangan nilai budaya dan tradisinya harus memiliki pondasi dari asalnya misal Jawa seseorang harus tahu unggah ungguh dan berbahasa Jawa yang baik dan benar dan di sisi lain tidak gagap dalam perkembangan global. Beliau juga mengatakan nilai ketimuran saat initerus menjadi baik dan memiliki sejarah panjang dan barat memiliki pondasi yang kuat dalam cara berpikir maka hal ini dapat diterpakan untuk generasi millennial saat ini dengan menyerap dari barat secara utuh dalam cara berpikir dan melampirinya dengan pondasi timur, Jawa nusantara hal ini menjadi sinergi kuat dalam memabangun generasi millennial dari setiap anacaman contoh Jawa jika di pengaruhi oleh Cina akan terlihat kejawaannya karena bekal yang sudah ditanamkan sejak awal yaitu "ngeli neng aja nganti keli" yang artinya ikuti aus tapi jangan sampai terhanyut,dalam hal ini peran orang tua sebagai contoh juga berpengaruh dalam keteladanan menyikapi budaya dan tradisi. ${ }^{11}$

Mengatur perilaku masyarakat yang memiliki tata nilai yang baik adalah salah satu makna pentingnya budaya bagi masyarakat untuk kehidupan bernegaranya. ${ }^{12}$ Sebagai warga dan masyarakat yang baik harus memiliki rasa cinta terhadap budaya nusantara. Pemerintah Indonesia pun juga mengakui pentingnya memiliki nilai budaya yang intelektual untuk kehiduapan bernegara, ${ }^{13}$ seperti di mulai dari hal kecil dengan mempelajari budaya lokal contohnya tradisi punggahan banyak sekali manfaat ketika mempelajari tradisi ini seperti dapat mengenal lebih dalam tentang budaya dan tradisi di sekitar kita, dapat memnciptakan hubungan yang baik antar manusia dan kelompok serta dapat lebih jauh memahami makna di balik sebuah tradisi dan melestarikan sebuah tradisi yang sudah ada sejak dulu ${ }^{14}$

Kutipan dari suara merdeka bahwa di Desa Bedono Kecamatan Jambu Kabupaten Semarang telah ditemukan bongkahan batu yang diduga struktur candi besar, Posisinya berada di lingkungan Bedono serta pas pada tikungan jalan penghubung Bedono-Lanjan (Sumowono). Berdasarkan strukturnya bantuannya situs candi ini sudah ada pada masa Jawa Kuna yaitu pada periode Hindu-Budha, serta dilihat dari panjang strukturnya memang

\footnotetext{
${ }^{10}$ Kaidah Hukum Islam "Ilmu Ushul Fiqh" (Jakarta: PT Grafindo Persada, 1993), 133.

${ }^{11}$ Menjadi Generasi Muda Yang Tetap Menjaga Budaya (Semarang: Net Biro Jawa Tengah, 2019).

${ }^{12}$ Iin Wariin Basyari, "Nilai-Nilai Kearifan Lokal (Local Wisdom) Tradisi Memitu Pada Mayarakat Cirebon" 2 (2014): 1.

13 Afifah Kusumadara, "Pemeliharaan Dan Pelestarian Pengetahuan Tradisional Indonesia : Perlindungan Hak Kekayaan Intelektual Dan Non-Hak Kekayaan Intelektual," Jurnal Hukum IUS QUIA IUSTUM 18 (2011): 3.

${ }^{14}$ Wawancara Tentang Tradisi Punggahan, February 4, 2020, Bedono.
}

53 | Salma Az-Zahra Ramadhani \& Nor Muhammad Abdoeh, - Tradisi Punggahan Sebelum Ramadhan 
diduga dulunya berwujud candi besar dan temuan ini termasuk temuan yang cukup besar di Kabupaten Semarang. ${ }^{15}$

\section{Data Informan / Narasumber}

1. Nama: Ahmad Dimyati

Umur : 46 tahun

Status : Tokoh Agama Kabupaten Semarang

2. Nama : Sodin

Umur : 40 tahun

Status : Kepala Dusun Wonokasihan (salah satu Desa di Bedono)

3. Nama : Siti Alfijah

Umur : 43 tahun

Status : Masyarakat Kabupaten Semarang

\section{METODE PENELITIAN}

Data kualitatif adalah penelitian dimana instrumen kunci dipegang oleh peneliti untuk meneliti suatu objek. Data kualitatif adalah data yang bukan berupa simbol atau angka melainkan berbentuk informasi atau kalimat. ${ }^{16}$ Untuk mendapatkan data kualitatif dapat dilakukan proses analisis wawancara. Dalam tradisi Punggahan di Desa Bedono Kecamatan Jambu Kabupaten Semarangmelalui wawancara dengan Bapak Sodin Kepala Dusun Wonokasihan yaitu salah satu dusun di Desa Bedono di dapatkan hasil wawancara bahwa menurut Bapak Sodin tradisi punggahan ini sudah lama dilangsungkan di Desa Bedono dan di laksanakan satu hari sebelum bulan Ramadhan di akhir bulan Ruwah guna menjalin tali silaturahmi antar sesama dan wujud rasa syukur kepada Allah SWT karena sudah di pertemukan lagi oleh bulan Ramadhan. Bapak Sodin juga menuturkan bahwa punggahan ini sebagai pembersih hati dengan setiap makna yang ada di dalam makanan yang dibawa ketika melakukan punggahan. ${ }^{17}$

\section{PEMBAHASAN}

\section{Profil Desa Bedono kecamatan Jambu Kabupaten Semarang Sejarah Desa Bedono}

Konon, pada masa penjajahan Belanda Ki subekti dari prajurit Pangeran Diponegoro melarikan diri dari kejaran para penjajah dan menemukan mata air sebumen yang berada di Desa bedono, di desa ini ada delapan dusun diantaranya Wawar, Karang Anyar, Jeruk Wangi, Wonokasian, Jurang,Krajan dan Lendoh. ${ }^{18}$ Dusun Wawar sendiri dulunya menjadi satu namun sekarang terpisah menjadi dua, yakni Wawar Lor dan Wawar Kidul. Cerita yang berkembang dimasayarakat Ki Dalemjaya menjadi orang pertama yang menempati dusun itu dan membuka hutan untuk memperluas desanya dan semakin lama desa tersebut semakin ramai dan

\footnotetext{
${ }^{15}$ Ranin Agung, "Situs Yoni Bedono Diduga Merupakan Struktur Candi Besar," n.d., https://www.suaramerdeka.com/news/baca/205483/situs-yoni-bedono-diduga-merupakan-struktur-candibesar.

16Sugiyono, Statistika Untuk Penelitian (Bandung: Penerbit AlfaBeta, 2017), 18-20.

${ }^{17}$ Sodin, Wawancara Tentang Tradisi Punggahan4 Febuari 2020 di Rumah Kepala Dusun.

18 “Tanggap Warsa Selangkungan Warsa Geber Skerem Kethoprak Bedono 2005.”
} 
nama Wawar sendiri berasal dari Nyai Awar-awar yaitu salah satu tokoh didesa itu. $^{19}$

Ki Budhiyoso menetap dan menimba ilmu kebatinanya di Dusun Karang Anyar, nama Karang Anyar sendiri berasalah dari seseorang yang melarikan diri dari Magelang dari kejaran Belanda yag bernama Ki Joproyo, lalu Ki Joproyo membuat tanah yang luas dan baru yang di sebut "pekarangan anyar" sehingga disebutlah Dusun Karang Anyar.

Putra dari Ki Joproyo yang bernama Mbah Grembul tinggal di sebalah Dusun Karang Anyar yang di Dusun tersebut terdapat gua yang di dalam gua tersebut terdapat bau wangi. Dusun sebelah Karang Anyar tadi disebut Dusun Jeruk Wangi karena berasal dari dalam gua tadi yaitu "njero wangi " atau dalam bahasa Indonesia dalamnya wangi maka dari itu jadilah nama Dusun Jeruk Wangi. ${ }^{20}$

Putri dari Roro Jonggrang yang bernama Mbok Randha Kasihan dikejar oleh Wanalaba sampai ke Yoni Kentheng Bedono yaitu salah satu situs candi yang ada di Bedono. Sampai akhirnya Mbok Randha Kasihan Menghabiskan masa hidupnya dan meninggal di daerah yang sekarang bernama Dusun Wonokasihan. Ki Wonolobo membawa jasad Mbok Randha Kasihan kembali ke Kediri dan setelah itu Ki Wonolobo kembali lagi ke Wonokasihan hingga wafatnya. Asal nama Dusun Wonokasihan ini berasal dari kata "wono" yang artinya hutan dan "kasib" yang artinya kliwon, kliwon ini merupakan hari meninggalnya Mbok Randha Kasihan pada waktu itu. ${ }^{21}$

Jurang adalah salah satu nama Dusun yag ada di Desa Bedono asal nama dusun ini dari kisah Ki Wanehjaya yaitu putra dari Sunan Gunung Jati, putra dari salah satu walisongo itu juga melarikan diri dari kejaran tentara Belanda sampai jatuh kejurang sehingga muncullah desa yang bernama Jurang. ${ }^{22}$

Kerbau landah yang hidup di dekat mata air yang ada di Desa Bedono itu populasinya sangat banyak sehingga nama Desa yang dulunya tempat para Kerbau Landah bermukim sekarang dinamakan Dusun Lendoh karena berasal dari Kerbau Landah tadi. Krajan sendiri adalah Dusun yang didalamnya terdapat situs Yoni Kentheng yang menurut sejarahnya candi ini dibangun bersamaan dengan Candi Dieng, dan Gedong Songo yang di bangun menurut tata cara Hindu. ${ }^{23}$

\section{Letak Geografis Desa Bedono}

Bedono merupakan salah satu Desa yang ada di Kecamatan Jambu Kabupaten Semarang yang berada di Km.10 antara Ambarawa dan Magelang, yang secara geografis terletak pada 7,3078 LS dan 110,3492 BT. Yang wilayanya berbatasan dengan desa lain seperti, Sebelah Utara berbatasan dengan Desa Kebondalem, Sebelah Selatan berbatasandengan Desa Gemawang, Sebelah Timur

\footnotetext{
19 “Tanggap Warsa Selangkungan Warsa Geber Skerem Kethoprak Bedono 2005."

20 "Tanggap Warsa Selangkungan Warsa Geber Skerem Kethoprak Bedono 2005."

21 "Tanggap Warsa Selangkungan Warsa Geber Skerem Kethoprak Bedono 2005."

22 "Tanggap Warsa Selangkungan Warsa Geber Skerem Kethoprak Bedono 2005."

23“'Tanggap Warsa Selangkungan Warsa Geber Skerem Kethoprak Bedono 2005."
} 
berbatasan dengan Desa Kelurahan dan Sebelah Barat berbatasan dengan Desa Rejosari. $^{24}$

Desa bedono sendiri terletak di daerah lereng atau puncak dengan ketinggian 711 meter di atas permukaan laut dengan titik koordinat $7^{\circ} 18^{\prime} 34^{\prime \prime}$ Selatan, $110^{\circ} 20^{\prime} 46^{\prime \prime}$ Timur. ${ }^{25}$ Menurut topografi dan luas wilayahnya 816,96 ha dengan kawasan pertanian 702,71 ha dan kawasan yang bukan pertanian 159,25 ha dan terdiri dari 8 Dusun dan $8 \mathrm{RW}$ serta $57 \mathrm{RT}^{26}{ }^{26}$

\section{Data Kependudukan Desa Bedono}

Desa Bedono mempunyai jumlah penduduk 9636 jiwa dengan jumlah LakiLaki 4815 dengan presentase $40 \%$ dan jumlah penduduk 4821 Perempuan dengan presentase $50 \%$, untuk AgamA sendiri di Bedono ada Islam,Kristen,Katolik,Budha dan Kerpercayaan lainnya jumlah penduduk yang beragama Islam 8813 dengan presentase 91,4 \%, jumlah penduduk Agama Kristen 34 dengan presentase 0,34\%, jumlah penduduk beragama Katolik 695 dengan presentase 7,1\%, jumlah penduduk beragama Budha 88 dengan presentase $0,9 \%$ dan jumlah penduduk dengan Kepercayaan lainnya 6 dengan presentase 0,06. Untuk pekerjaan masyarakat Bedono sendiri paling banyak bekerja sebagai Wiraswasta dengan jumlah 1787 dengan presentase 32,14\%, sebagai Karyawan Swasta jumlah penduduk 1576 dengan presentase 28,34\%,penduduk yang berkerja sebagai Petani 1638 dengan presentase 29,46\%, jumlah penduduk yang menjadi Buruh 332 dengan presentase $5,97 \%$, jumlah penduduk dengan mata pencarian sebagi seorang Pedagang sebesar 89 dengan presentase 1,6\%, serta jumlah penduduk yang mengabdikan dirinya sebagai Guru dan Pegawai Negeri Sipil yaitu masing masing 69 orang dengan presentase $1,24 \% .^{27}$

\section{Proses pelaksanan Punggahan di Desa Bedono}

Punggahan adalah sebuah tradisi menjelang bulan suci Ramadhan dengan mengirim doa kepada orang yang sudah meninggal atau Pak Sodin sebagai Kepala Dusun sering menyebutnya "bebak cidak " atau dalam arti lain nenek moyang dan para leluhur dengan mengadakan tahlilan dan membawa beberapa makanan yang memiliki makna masing-masing disetiap makanan yang dibawa oleh penduduk desa. $^{28}$

Desa Bedono Kecamatan Jambu Kabupaten Semarang biasnya pelaksanaan tradisi Punggahn ini pada satu atau dua hari menjelang bulan suci Ramadhan. Momen ini diperingati masyarakat dengan melakukan tahlilan dengan membawa beberapa diantaranya yaitu Ketan, Apem, Pisang, Pasung dengan makna yang terkandung dalam setiap makanan tersebut.

\footnotetext{
24“Data Kependudukan Dari Pemerintah Desa Bedono Kecamatan Jambu Kabupaten Semarang,” n.d.
}

\footnotetext{
26 "Data Kependuduakn Dari Pemerintah Desa Bedono Kecamatan Jambu Kabupaten Semarang."

27"Data Kependudukan Dari Pemerintah Desa Bedono Kecamatan Jambu Kabupaten Semarang."

${ }^{28}$ Sodin, Wawancara Tentang Tradisi Punggahan4 Febuari 2020 di Rumah Kepala Dusun.
} 
Ketan merupakan kata yang berasal dari bahas Melayu yang kemudian ditafsirkan dengan kata "khotho'an" yang berarti kesalahan, Apem ditafsirkan dengan lafadz "afwan" yang berarti maaf. Sebagai sesama manusia harus saling maaf memaafkan selain bertaubat kepada Allah SWT, Pisang dalam bahasa Arab yaitu "ghodaan" yang memiliki arti esok hari atau waktu yang akan datang, dan Pasung ditafsirkan dengan lafadz "fashoum" yang mempunyai arti maka berpuasalah, berpuasa dilakukan setelah bertaubat dan minta maaf demi menyempurnakan keduanya. ${ }^{29}$

Pelaksanakantradisi punggahan ini biasanya masyarakat Desa Bedono melakukannya di salah satu rumah penduduk yang memang saat itu berketempatan untuk yasinan rutin pada malam Jum'at atau di Masjid dan MusholaBiasanya masyarakat membawa makanan tersebut menggunakan "tenggok" sebuah tempat yang berasal dari anyaman bambu ataupun di bawanya menggunakan baskom, dengan penataan dalam wadah tersebut ketan di taruh paling bawah dengan setengah menutupi permukaan wadah, lalu Apem,Pisang, dan Pasung di tata di atasnya sehingga menutupi ketan atau terkadang ada juga masyarakat yang membuat ketan menjadi tumpeng kecil dan menaruh makanan lainnya di sekeliling tumpen ketan tersebut. Sebenarnya tidak ada syarat dalam penataan makanan tersebut hal ini dilakukan sesuai dengan kehendak masing-masing penduduk yang melakukan tradisi ini. ${ }^{30}$

Tradisi punggahan ini dilaksanakan karena menyambut bulan suci Ramadhan dan sudah ada sejak dahulu tujuannya untuk mendoakan arwah arwah leluhur yaitu "bebak cidak" atau dalam arti lain nenek moyang (mendoakan nenek moyangMenurut Bapak Sodin sesepuh desa tradisi ini sudah lama dilakukan di Desa Bedono serta dapat menjalin keakraban sesama masyarakat atau sesama tentanggaserta membersihakan hati dari segalan kesalahan. Peserta dari tradisi punggahan ini adalah semua masyarakat yang beragama Islam dan semua lapisan mengikuti seperti bapak bapak, ibu ibu, pemuda pemudi bahkan anak anak juga ikut merayakan tradisi ini, kecuali yang pada hari itu tidak sedang ada di rumah. ${ }^{31}$

Prosesi ini dilakukan biasanya di Masjid dan Mushola acaranya biasanya sesudah terawaih pertama dilaksanakan slametan dengandengan membaca tahlil terlebih dahulu dengan semua makanan yang di bawa di taruh didepannya setelah proses tersebut masuk ke proses puncak yaitu semua masyarakat menjadikan satu makanan yang mereka bawa sedekah alakadar kalau dulu biasanya ada ketan, apem pasung, gedang rojo (pisang raja) dan pisangnya pun dianjurkan pisang araja namun sekarang berkembangnya zaman kadang ada yang bawa roti, camilan kering kadang juga ada yang bawa buah semangka jerukjuga biasanya disitu dijadikan satu lalu nanti dimakan bersama kalo itu tidak habis baru di bawa pulang dengan misal seseorang membawa ketan ketika berangkat namun setelah acara selesai bisa

\footnotetext{
${ }^{29}$ Sodin.

${ }^{30}$ Sodin.

31 Sodin.
}

57 | Salma Az-Zahra Ramadhani \& Nor Muhammad Abdoeh, - Tradisi Punggahan Sebelum Ramadhan 
membawa pulang buah bisa bertukar dengan orang lain begitu ucap Bapak Sodin sebagai seorang Kepala Dusun. ${ }^{32}$

\section{Makna Tradisi Punggahan di Desa Bedono}

Punggaban itu artinya naik ketempat yang lebih tinggi dari bulan Sya'banyang sering disebut juga bulan Ruwah bagi masyarakat Jawa bulan ini berasal dari kata "ngeluru" yang berarti mencari dan "arwah" yang berarti arwah bahwa pada Bulan Ruwah (Sya'ban) masyarakat sering melakukan tradisi punggahan setiap tahunya ${ }^{33}$ untuk masuk ke bulan suci Ramadhan yaitu bulan yang penuh rahmat dan magfiroh. Pada saat bulan Ramadhan orang yang beribadah Sunnah akan diberi pahal seperti melaksanakan ibadah Wajib dan orang yang melaksanakan ibadah Wajib akan di lipat gandakan sepuluh kali pada bulan yang sangat agung dan tidak ada bandingannya ini. Dalam tradisi punggahan ini dapat menjadi ajang silaturahmidan mempererat tali silaturahmi karena masyarakat desa yang ada di luar desa atau bahkan luar kota mereka rela pulang dan meluangkan waktunya demi mengikuti tradisi sebelum bulan suci Ramadhan, dari hal ini banyak sekali makna yang terkandung di dalam tradisi punggahan ini masyarakat bisa saling bermaaf maaf-an, bercengkarama satu sama lain sehingga tidak sudah tidak ada dendam di dalam hati mereka saat memasuki bulan suci Ramdhan. ${ }^{34}$

Dalam tradisi punggahan ini memang mengirim doa untuk orang yang sudah meninggal namun melalui rumah, Masjid atau Mushola dengan membawa makanan seperti ketan, pisang, apem,pasung saja dan tidak harus pergi kemakam, tetapi dalam hal ini tidak dilarang untuk menjelang Ramadhan kita berzaiarah ke makam orang terkasih kita yang sudah meninggal.

Makanan yang harus di bawa saat tradisi punggaban ini menurut Sodin memiliki makna tersendiri disini akan di jelaskan satu persatu seperti penjelasan dibawah ini. ${ }^{35}$

Ketan mirip dengan beras yang termasuk kedalam kelompok biji-bijian serelia yang ukurannya agak besar, bulat dan lonjong serta warna ketan yang putih susu ini seperti melambangkan kesucian yang akan diperoleh oleh masyarakat sebelum memasuki bulan Ramadhan denganKetan dari Bahas Arab yaitu dari kata "Qhotoan" yang artinya kotoran jika kita banyak kesalahan terhadapa sesama manusia maupun kepada Allah SWT menjelang itulah kita untuk membersihkan diri dengan cara bersedekah lewat tradisi punggahan ini.

Menurut Sodin Makanan yang terbuat dari tepung beras ini banyak orang menyebutnya Apam atau Apem yang campuran didalamnya terdiri dari telur, gula, santan, tape dan garam ini bentuknya hampir menyerupai serabi yang sering kita jumpai serta cara memasakanya dengan dikukus. Apem sendiri termasuk dalam

\footnotetext{
${ }^{32}$ Sodin.

${ }^{33} Y$ uhana, "Tradisi Bulan Ramdhan Dan Kearifan Budaya Komunitas Jawa Di Desa Tanah Datar Kecamatan Rengat Barat Kabupaten Indaragiri Hulu," Jurnal Online Mahasiswa Fakultas Ilmu Sosial Dan Imu Politik Universitas Rian 3 (2016): 9.

34“"Punggahan Itu Tradisi Atau Ibadah?," Mamah Dan Aa Beraksi (Jakarta: Indosiar, 2018).

35 Sodin, Wawancara Tentang Tradisi Punggahan 4 Febuari 2020 di Rumah Kepala Dusun.
} 
makanan di dalam tradisi punggahan agarApem dari Bahas Arab yitu dari kata ” Afwan" yang artinya maaf atau ampunan, artinya sebelum memasuki bulan Ramdhan kita harus memohon ampun kepada sang Khaliq $^{36}$

Kue pasung pasung yang bentuknya seperti contong namun itu aslinya juga apem hanya saja bentuknya yang berbeda pasung itu diambil dari Bahas Aranya puasa yaitu "fashoum" atau kalau dalam Bahasa Jawa pasung itu maknannya untuk mengikat atau memasung diri kita dari hawa nafsu jadi hawa nafsu itu dipasung agar hawa nafsu itu ketika memasuki bulan suci Ramadhan tidak melakukan hal-hal yang diluar ajaran agama atau melanggar syariat agama Islam termasuk juga memasung amarah agar ketika Ramadhan hati kita lebih sabar dengan segala apa pun itu yang sedang kita jalani. ${ }^{37}$

Salah satu buah yang termasuk dalam list makanan yang harus dibawa ketika punggahan ini berbentuk lonjong dan berwarna kuning ketika matang dan warna hijau untuk yang belum matang. Buah yang memiliki biji lembut ini baik untuk kesehatan dan makna yang terkadung bahwa Gedang rojo itu berasal dari Bahasa Arab yaitu "ghodhan roja'a" bahwa kita punya harapan agar diberikan apa yang kita minta kepada Allah SWT di kabulkan memohon agar besok saat memasuki bulan Ramadhan dengan makna ketan tadi qotoan yang artinya kotoran, apem yang artinya afwan, pasung yang artinya memasung hawa nafsu, Bahwa semoga harapan dari makna makanan diatas dapat dikabulkan. ${ }^{38}$

Pendapat dari Bapak Sodin di atas bahwa makanan yang dibawa pada dasarnya sebagai simbol datangnya bulan suci Ramadhan yang diperintahakan untuk kita mensucikan diri, saling memaafkan terhadap sesama dan memohon ampunan kepada Allah SW'T. ${ }^{39}$

Mengenai ziarah dan tahlil dalam tradisi punggaban di jelaskan oleh salah satu tokoh agama Ahmad Dimyati tentang tradisi yang ada di nusantara beliau mengutip Riwayat Imam al-Tirmidzi, 974. " Aku telah melarang kalian ziarah kubur, dan (sekarang) telah diizinkan bagi Muhammad untuk berziarah kemakam ibunya, maka berziaralah kalian semua, karena di dalamnya (ziarah kubur) dapat mengigatkan akhirat". Maka sesungguhnya tradisi berziarah menjelang Ramadhan ini tidak bertentangan dengan perilaku keadaban manusia itu dan tidak bertentangan dengan syariat agama Islam. Beliau juga menuturkan Tahlilan yang sering dilakukan saat ziarah dan yasinan di rumah ini adalah sebuah tradisi yang dilakukan oleh masyarakat Indonesia. Di dalam tahilan terdapat pembacaan doa, pembacaan Takbir, pembacaan Tahmid dan doa-doa yang lain, meskipun secara tersurat Rasulah SAW. Tidak pernah mengerjakan bacaan Tahlil ini, namun tidak ada satupun bacaandalam Tahlil yang bertentang dengan syariat Islam. Semua yang dibaca merupakan doa dan dzikir yang pada dasarnya sangat dianjurkan dalam agama Islam.

\footnotetext{
${ }^{36}$ Sodin.

37 Sodin.

${ }^{38}$ Sodin 4 Febuari 2020 di Rumah Kepala Dusun.

${ }^{39}$ Sodin.
}

59 | Salma Az-Zahra Ramadhani \& Nor Muhammad Abdoeh, - Tradisi Punggahan Sebelum Ramadhan 
Ahmad Dimayati menegaskan dengan pendapat Al imam syaukani dimana segala sesuatu (termasuk kegaiatan) yang didalamnya terdapat bacaan al-Quran, Dzkir dan Doa, hal ini merupakan perbuatan yang baik, meskipun Rasullah SAW. Belum pernah melakukannya. Beliau juga menambahkan permasalah yang sering beliau hadapi ketika masyarakat bertanya bahwa kenapa Tahlil dilakukan sampai tujuh hari dari kematian ? kenapa tidak hanya sekali ? dalam menjawab pertanyaan itu beliau menegaskan bahwa tidak ada ketentuan paten dan mengikat yang berkenaan dengan waktu pembacaan Tahlil, andaikan ada orang yang melakukan Tahlil setap hariuntuk orang yang meninggal dunia, maka hal tersebut tetap di perbolehkan, beliau juga menambahkan sebuah Riwayat dari Thawus yakni “ Sesungguhnya orang-orang yang meninggal dunia, mereka diberi cobaan (oleh Allah SWT) selama tujuh hari, maka mereka (para ulama), senang memberikan makanan (bersedekah, keapada orang lain) bagi orang yang telah meninggal dunia pada saat tujuh hari ini. Beliau menambahkan bahwa Riwayat ini dapat ditemukan dalam kitab Hilyatu al-Auliya', Juz 4 halaman 11.

Masih dalam pendapat Ahmad Dimayati bahwa sebagian orang masih banyak saja yang bersikukuh melarang Tahlilan, dengan landasan pendapat Imam Syafi'i berkenaan dengan Ma'tam. Padahal, jika diamati kembali yang dimakasud dengan Ma'tam menurut Imam Syafi'i adalah perekumpulan sekelompok orang yang meratapi kepergian kerabatanya yang meninggal dunia, serta menangisinya. Semetara menurut beliau tahlilan justru merupakan perkumpulan yang didalamnya dilakasanakan pembacaan Doa, pembecaan Dzikir, pembacaan Yasiin dan lain sebagainya. Bahkan dari segi sosial tidak jarang acara Tahlilan ini justru menjadi salah satu sebab tumbuhnya rasa sosial diantara masyarakat. Paparan diatas, masih termasuk salah satu alasan masyarakat Indonesia sampai sekarang Tahlilan, sebenarnya masih ada alasan lain yang menjadi alasan tahlilan. ${ }^{40}$

\section{Pandangan Islam tentang Tradisi Punggahan}

Tradisi punggahan tidak ada dalam syariat islam bahkan Rasullah SAW tidak melakukan hal itu. Tetapi ada beberapa hikmah yang bisa di ambil dari tradisi ini yaitu saling memaafkan dan membersihkan jiwa dari segala kesalahan terhadap sesama untuk menyambut bulan suci dan bulan penuh rahmat yaitu bulan Ramadhan. ${ }^{41}$ Keberadaannya sangat di akui oleh masyarakat, Khususnya masyarakat di Jawa karena tradisi punggahan ini pertama kali diperkenalkan oleh Sunan Kalijaga.

Menurut pandangan para Kyai Nahdlatul 'Ulama ajaran Islam mengajakarkan bermasayarakat dengan tetap berpegang dengan tradisi atau kebiasaan (tingkah laku). Kebudayaan yang bersifat abstrak ini terletak pada pikiran manusia dengan ide dan gagasan yang kompleks. ${ }^{42}$ Perkembangan islam dan budayanya tidak bisa ditolak karena mereka murni berkembang dengan sendirinya. Budaya dan Islam tidak bisa di campur adukan tetapi Budaya dan Islam dapat

\footnotetext{
${ }^{40}$ Ahmad Dimyati, Wawancara tentang Tradisi Nusantara, February 2, 20202 Febuari 2020 di Rumah Suruh. ${ }^{41}$ Muhammad Rusli, Puasa (Jakarta: Pustaka Zahra, 2003), 15.

${ }^{42}$ Ali Anwar, Advonturisme NU (Nabdlatul 'Ulama) (Bandung: Humaniora Utama Press, 2013), 134.
} 
beriringan misalnya dalam Tradisi punggahan ini ada hal positif di dalam tradisi ini yang dapat di ambil pelajarannya untuk kehidupan bersama.

Kebiasaan yang membudaya ini dinamakan tradisi dikalangan masyarakat dalam menyambut datangnya bulan suci Ramadhan. ${ }^{43}$ terkandung dari makanan yang dibawa. Seperti firman Allah SWT. (Q.S. Al-Baqarah $2: 222$ )

$$
\text { 吕...... }
$$

Artinya : ........ Sesungguhnya Allah SWT. menyukai oarang-orang yang bertaubat dan mensucikan diri ${ }^{44}$

Ayat diatas menegaskan bahwa tradisi punggahan yang manfaatnya banyak terutama untuk orang-orang dengan saling memaafkan dan bertaubat kepada Allah SWT dan Allah SWT menyukai hal itu, hal-hal yang tidak bertentangan dengan agama tetapi malah sebaliknya membawa pengaruh yang baik dalam agama dan kehidupan.

Ahmad dimyati menambahkan dalam hal ini sesungguhnya tradisi yang tidak bertentangan dengan perilaku keadaban manusia itu tidak bertentangan dengan syariat Islam, dalam Qaidah Ushul Fiqih bahwa Al adatul hukmi adat itu bisa menjadi hukum seperti dalam tradisi Imam Syafi'i ada istilah Qoul Qodim dan Qoul Jadid adalah teks terdahulu dan teks baru. ${ }^{45}$

Rangkaian proses yang ada di punggahan salah satunya adalah Tahlilan yang terdiri dari membaca Tahlil, Tahmid, Tasbih dan Shalawat yang ini semua tidak ada yang melarang dalam agama serta tidak juga melanggar syariat agama Islam. ${ }^{46}$ Hadist Riwayat Al Hakim dan Baihaqi juga menjelaskan tentang Istigfar dimana istigfar juga salah satu rangkaian dari Tahlil saat Tradisi punggahan. "Bahwa pahala orang yang memeperbanyak Istigfar, Allah SWT akan jadikan bahagia di saat susah, Allah SWT akan jadikan jalan keluar dikala sempit dan Allah SWT akan memberikan rezeki yang tidak disangka-sangka" 47

Hadist Riwayat Tirmidzi dari Ibnu Hibban juga menjelaskan salah satu rangkaian dalam tahlil yaitu membaca Shalawat "Bahwa keutamaan pahala bagi orang yang bershalawat akan bersama Nabi Muhammad SAW pada hari kiamat nanti”.

Ternyata jika ditelaah lebih mendalam ajakan para kiyai untuk berkumpul di masjid melaksanakan Punggahan merupakan ajaran mulai Rasullah SAW. Ungkapan kebahagiaan akan datangnya bulan suci Ramadhan ini dinamakan Tradidi Punggahan yang sekaligus mengajarkan masyarakatnya untuk bershadaqah terhadap sesama. Seperti firman Allah SWT (QS. Yunus 10:58)

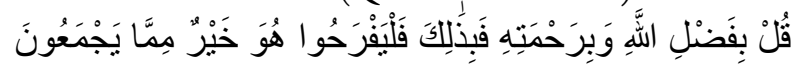

${ }^{43}$ Ahmad Rifa’i Rifan, Ramadhan Maaf Kami Masib Sibuke (Jakarta: PT Elex Media Komputindo, 2017), 25.

${ }^{44}$ Al-Quran Dan Terjemah (Surakarta: Pustaka Al-Hanan, 2015) QS.Al-Baqarah 2/222.

${ }^{45}$ Ahmad Dimyati, Wawancara tentang Tradisi Nusantara2 Febuari 2020 di Rumah Suruh.

46Abu Abdillah, Argumen ASW AJA (Tangerang Selatan: Pustaka Ta'awun, 2011), 258.

${ }^{47}$ Abdillah, 13. 
Artinya : Katakanlah dengan karunia Alah dan rahmatNya, hendaklah dengan itu mereke bergembira. Kurnia Allah dan rahmat-Nya itu adalah lebih baik dari apa yang mereka kumpulkan. ${ }^{48}$.

Hasil wawancara dengan Ibu Siti Alfijah, beliau menambahkan bahwa para wali telah melakukan Islamisasi terhadap tradisi yang berkembang di Nusantara sejak ratusan tahun silam. Dengan demikian, tradisi tersebut sama sekali tidak bertentangan dengan ajaran Islam. Jadi, meskipun tradisinya bisa saja merupakan warisan atau tinggalan agama lain, tetapi ruhnya tetap sejalan dengan ajaran Islam. Tradisi - tradisi baik akan dilesatraikan hingga saat ini, walaupun secara lahiriah tidak diubah sama sekali, tetapi isinya yang semula mengandung akidah agama lain seudah diubah sesuai ajaran Islam mislanya Tradisi punggahan ini. ${ }^{49}$

\section{Manfaat mempelajari Tradisi Punggahan}

Negara kepulauan yang terbentang dari Sabang sampai Merauke ini memiliki beraneka ragam suku, budaya dan tradisi hal ini menjadi kekayaan yang perlu dilestarikan keberadaanya. Sebagai warga negara yang baik kita harus menjaga budaya dan tradisi yang sudah ada sejak dahulunya seperti yang dibahas diatas yaitu Tradisi punggahan, banyak sekali hal yang bermanfaat ketika mempelajari Tradisi ini dengan memepelajarinya kita dapat mengetahui makna yang terkandung dalam tradisi itu. Hasil wawancara dengan Ibu Siti Alfijah bahwa mempelajari sebuah Budaya dan tradisi dapat mengetahui tentang asal usul tradisi yang berkembang di nusantara, serta dapat juga memilih mana tradisi yang baik untuk dilestarikan dan mana tradisi yang tidak perlu dilestariak karena tidak sesuai dengan perkembangan zaman dan Ibu Siti Alfijah juga menambahkan dalam mempelajari sebuah tradisi kita mendapat pelajaran berharga dari semua tradisi yang ada di nusantara terutama dengan tradisi pungghan ini. ${ }^{50}$

Tradisi punggahan bukan saja menjadi tradisi biasa namun tradisi masayarakat Jawa ini memberi banyak manfaat yang sangat luas tergantung pada keinginan dan intuisi masing-masing dan makna. ${ }^{51}$ Diantaranya dapat mempererat tali silaturahmi baik dengan keluarga, sahabat, teman bahkan tetangga sendiri, Saling memaafkan antar sesama sehingga mempunyai hati yang bersih untuk memulai ibadah puasa serta ungakapan rasa bersyukur kepada Allah SW'T yang telah memberi segala karunia dan nikmat untuk kita para hambanya ${ }^{52}$

Mempererat kolektif antar manusia hingga dapat mengeluarkan diri dari kemiskinan Dapat direnungkan menjadi manfaat dalam tradisi ini. Tradisi punggaban juga dapat menaikan nilai-nilai kemanusian kita. Maka dari itu bulan Ramadhan dapat dijadikan bulan untuk meninggalakan sifat-sifat seperti sombong, pelit, syirik, dan fitnah.

${ }^{48}$ Al-Quran Dan Terjemah QS.Yunus 10/58.

${ }^{49}$ Siti Alfijah, Makna Tradisi, February 5, 20205 Febuari 2020 di Rumah Suruh.

${ }^{50}$ Siti Alfijah.

${ }^{51}$ Mulyana, "Spiritualisme Jawa: Meraba Dimensi Dan Pergulatan Religiusitas Orang Jawa," Jurnal Kebudayaan Jawa, No 2, 1 (2006): 55.

${ }^{52}$ Komaruddin Hidayat, Dahsyatnya Syukur (Jakarta: QufHumMedia, 2009), 110-11. 
Tradisi punggahan sendiri memiliki makna untuk mengintropeksi kesalahan yang ada pada diri kita dan yang pernah dilakukan sebelumnya. Karena dalam memasuki bulan Ramadhan segala kesalahan dapat terampuni, serta dalam memasuki bulan Ramadhan kita dalam keadaan hati yang bersih. Nilai - nilai yang terkandung dalam mempererat tali silaturahmi diantara sesama umat Nabi Muhammad SAW. Inti dari punggahan sendiri yakni mempersiapkan diri menjadi hati yang rasa empati dan kolektivisme tinggi. Karena Allah SWT mewajibkan hambanya atau seluruh umat islam di dunia untuk melakukanpuasa di bulan Ramadhan $^{53}$ hal ini dapat menyadarkan bahwa kita juga harus merasakan penderitaan sesama yang terkadang orang untuk makan saja susah atau tidak dapat membeli makanan sehari-hariya.

Dengan ini, tradisi sederhana ini harus tetap dilestarikan dan di jaga agar bisa tetap dapat diketahui oleh generasi mendatang. khususnya bagi masyarakat di Jawa. Hal ini juga dituturkan oleh Bapak Sodin sebagai Kepala Dusun bahwa tradisi ini harus tetap di lestarikan, ${ }^{54}$ karena tradisi ini memiliki banyak manfaat dan makna tersendiri dan menjaga tradisi yang ada di nusantara merupakan salah satu cara untuk tetap menjaga warisan yang ada di negeri ini agar dapat dinikmati oleh dunia dan generasi mendatang. Intinya, dengan punggahan dapat mempererat tali silaturahmi antar sesama, mensucikan hati, meningkatkan rasa syukur dan menghilangkan sifat-sifat yang seharusnya tidak ada dalam diri masyarakat Indonesia.

\section{KESIMPULAN}

Desa Bedono Kecamatan Jambu Kabupaten Semarang biasanya melaksanakan tradisi Punggahan pada satu atau dua hari menjelang bulan suci Ramadhan. Momen ini diperingati masyarakat dengan melakukan tahlilan dengan membawa beberapa diantaranya yaitu Ketan, Apem, Pisang, Pasung dengan makna yang terkandung dalam setiap makanan tersebut. Punggahan itu artinya naik ketempat yang lebih tinggi dari bulan Sya'ban bulan yang biasa masuk ke bulan suci Ramadhan yaitu bulan yang penuh rahmat dan magfiroh. Tradisi ini dapat menjadi ajang silaturahmi dan mempererat tali silaturahmi karena masyarakat bisa saling bermaaf maaf-an, bercengkarama satu sama lain sehingga sudah tidak ada dendam di dalam hati mereka saat memasuki bulan suci Ramdhan Tradisi Punggahan tidak ada dalam syariat Islam bahkan Rasullah SAW tidak melakukan hal itu. Namun tradisi ini tidak ada masalah dilakukan selagi kegiatan ini di isi dengan hal-hal positif dan tidak melanggar syariat agama Islam. Manfaat tradisi Punggahan yaitu mempererat tali silaturahmi baik dengan keluarga, sahabat, teman bahkan tetangga sendiri, saling memaafkan antar sesama sehingga mempunyai hati yang bersih untuk memulai ibadah puasasebagaibentuk rasa syukur kepada Allah SWT.

\footnotetext{
${ }^{53}$ Abu Maryam Kautsar Amru, Memantaskan Diri Menyambut Bulan Ramadhan (Jakarta: Kautsar Amru Publishing, 2018), 18.

${ }^{54}$ Sodin, Wawancara Tentang Tradisi Punggahan4 Febuari 2020 di Rumah Kepala Dusun.
} 


\section{REFERENSI}

Abdillah, Abu. Argumen ASW AJA. Tangerang Selatan: Pustaka Ta'awun, 2011.

AG, Muhaimin. Islam Dalam Bingkai Budaya Lokal Potret Dari Cirebon, Terj. Suganda.

Ciputat Tangerang: PT Logos Wacana Ilmu, 2001.

Ahmad Dimyati. Wawancara tentang Tradisi Nusantara, February 2, 2020.

Al-Quran Dan Terjemah. Surakarta: Pustaka Al-Hanan, 2015.

Amru, Abu Maryam Kautsar. Memantaskan Diri Menyambut Bulan Ramadhan. Jakarta:

Kautsar Amru Publishing, 2018.

Anhari, Maskhur. Usbul Fiqh. Surabaya: CV Smart, 2008.

Anwar, Ali. Advonturisme NU (Nabdlatul Ulama). Bandung: Humaniora Utama Press, 2013.

Arifin, Bey. Hidup Setelah Mati. Jakarta: Pt Dunia Pustaka, 1984.

"Data Kependuduakn Dari Pemerintah Desa Bedono Kecamatan Jambu Kabupaten Semarang," n.d.

Efendi, Satria. Ushul Fiqh. Jakarta: Grafindo Pustaka, 2005.

Hidayat, Muhammad Nur. Lebih Dalam Tentang Nabdhatul 'Ulama. Surabaya: Bina Aswaja, 2012.

Khalil, Rasyad Hasan. Tarikh Tasyri. Jakarta: Grafindo Persada, 2009.

Khallaf, Abdul Wahab. Kaidah Hukum Islam "Ilmu Ushul Fiqh". Jakarta: PT Grafindo Persada, 1993.

Komaruddin Hidayat. Dahsyatnya Syukur. Jakarta: QufHumMedia, 2009.

Kuntowijaya. Budaya Dan Masyarakat. Yogyakarta: Tiara Wacana, 2006.

Kusumadara, Afifah. "Pemeliharaan Dan Pelestarian Pengetahuan Tradisional

Indonesia : Perlindungan Hak Kekayaan Intelektual Dan Non-Hak Kekayaan Intelektual.” Jurnal Hukum IUS QUIA IUSTUM 18 (2011): 3.

Ma'arif, Ahmad Syafie. Menembus Batas Tradisi Menuju Masa Depan Yang Membebaskan Refleksi Atas Pemikiran Nur Cholis Majid. Jakarta: Penerbit Buku Kompas, 2006.

Menjadi Generasi Muda Yang Tetap Menjaga Budaya. Semarang: Net Biro Jawa Tengah, 2019.

Mulyana. "Spiritualisme Jawa: Meraba Dimensi Dan Pergulatan Religiusitas Orang Jawa." Jurnal Kebudayaan Jawa, No 2, Vol 1 (2006): 55.

"Punggahan Itu Tradisi Atau Ibadah?" Mamah Dan Aa Beraksi. Jakarta: Indosiar, 2018.

Ranin Agung. "Situs Yoni Bedono Diduga Merupakan Struktur Candi Besar." n.d. https://www.suaramerdeka.com/news/baca/205483/situs-yoni-bedonodiduga-merupakan-struktur-candi-besar.

Rifan, Ahmad Rifa'i. Ramadhan Maaf Kami Masib Sibuk. Jakarta: PT Elex Media Komputindo, 2017.

Rusli, Muhammad. Puasa. Jakarta: Pustaka Zahra, 2003.

Sholikhin, Muhammad. Misteri Bulan Suro Prespektif Islam Jawa,. Yogyakarta: Penerbit Narasi, 2010. 
Siti Alfijah. Makna Tradisi, February 5, 2020.

Sodin. Wawancara Tentang Tradisi Punggahan, February 4, 2020. Bedono.

Sugiyono. Statistika Untuk Penelitian. Bandung: Penerbit AlfaBeta, 2017.

"Tanggap Warsa Selangkungan Warsa Geber Skerem Kethoprak Bedono 2005," 2005.

Wariin Basyari, Iin. "Nilai-Nilai Kearifan Lokal (Local Wisdom) Tradisi Memitu Pada Mayarakat Cirebon" 2 (2014): 1.

Yuhana. "Tradisi Bulan Ramdhan Dan Kearifan Budaya Komunitas Jawa Di Desa Tanah Datar Kecamatan Rengat Barat Kabupaten Indaragiri Hulu.” Jurnal Online Mahasiswa Fakultas Ilmu Sosial Dan Imu Politik. Universitas Riau Vol 3 No 1 (2016): 9. 